\title{
OS BLOGS COMO DIVULGADORES DE NOVOS PRODUTOS E INFLUENCIADORES DO CONSUMO DE MODA
}

THAISSA SCHNEIDER CENTRO UNIVERSITÁRIO - CATÓLICA DE SANTA CATARINA BLUMENAU, SANTACATARINA, BRASIL E-MAIL:THAI@TERRA.COM.BR

LAURA PEDRI PEREIRA CENTRO UNIVERSITÁRIO - CATÓLICA DE SANTA CATARINA JAGUARÁ DO SUL, SANTA CATARINA, BRASIL E-MAIL:LAURAPEREIRA@UNERJ.BR 
OS BLOGS COMO DIVULGADORES DE NOVOS PRODUTOS E INFLUENCIADORES DO CONSUMO DE MODA

Resumo: Com o atual crescimento dos blogs de moda no Brasil, a pesquisa visa descrever como seus autores tornaram-se líderes de opinião. Optou-se por utilizar a pesquisa bibliográfica e a pesquisa de campo através de um questionário eletrônico que totalizou 508 respostas. Os resultados também verificaram a preferência pelos blogs e suas publicações, sobretudo no que diz respeito à divulgação de produtos e sua influência nos leitores.

Palavras chave: Blogs de moda; Divulgação de produtos; Comportamento de consumo.

LOS BLOGS COMO DISEMINADORES DE NUEVOS PRODUCTOS E INFLUENCIADORES DE CONSUMO DE MODA

Resumen: Con el actual crecimiento de los blogs de moda en Brasil, la investigación pretende describir cómo los autores se han convertido en líderes de opinión. Se optó por utilizar la literatura y la investigación de campo a través de un cuestionario electrónico que totalizó 508 respuestas. Los resultados también comprobaran la preferencia por los blogs y publicaciones, especialmente con respecto a la promoción de productos y su influencia sobre los lectores.

Palabras clave: Blogs de moda; Promoción de productos; Comportamiento de consumo.

\title{
BLOGS AS DISSEMINATORS OF NEW PRODUCTS AND INFLUENCERS OF FASHION CONSUMPTION
}

\begin{abstract}
With the current growth of fashion blogs in Brazil, the research aims to describe how their authors have become opinion leaders. It was opted to use the bibliographic and field research through an electronic questionnaire which summed up 508 responses. The results also verified the preference for blogs and their publications, especially regarding the promotion of products and its influence on readers.
\end{abstract}

Keywords: Fashion blogs; Products advertising; Consumption behavior. 


\section{INTRODUÇÃO}

A difusão e popularização das tecnologias digitais fizeram com os blogs e websites pessoais ganhassem maior relevância a cada dia. Diante da "realidade jornalística", eles possuem uma resposta mais rápida e pessoal do que os meios de comunicação tradicionais, contribuindo para ampliar as fronteiras da realidade midiática. (ORDUÑA et al., 2007). Nesse espaço, o processo de publicação na rede é praticamente simultâneo à escrita, e esta característica se traduz na informalidade, na espontaneidade e no caráter pessoal, estilo dominante dos blogs. Considerado uma das ferramentas mais inovadoras do século, o blog desenvolveu sua própria linguagem e assim transformou a cultura, sobressaindo-se pelos atributos que permitem aos usuários a expressão, a opinião, o compartilhamento, a colaboração e a interação.

A blogosfera - universo e cultura dos blogs - é um sistema complexo e extraordinariamente dinâmico, e como todas as comunidades, também possui seus líderes. Atualmente, esses líderes são expressos pelas figuras das blogueiras de moda, que ao ditarem novas tendências e divulgarem novos produtos para o mercado, tornaram-se uma espécie de cyber-celebridades ${ }^{31}$ . Em anos anteriores ao boom dos blogs, esses grupos de referência eram formados por pessoas pertencentes às classes sociais com maior poder econômico ou celebridades do cinema. Agora, são constituídos por pessoas comuns que, de alguma maneira, são consideradas um best-seller de acessos.

Assim, observa-se o poder de influência desses líderes de opinião sobre o comportamento de consumo de novos produtos. Solomon (1996, p. 7 apud MIRANDA, 2008, p. 14) compreende o comportamento de consumo como o estudo "[...] dos processos onde os indivíduos ou os grupos selecionam, compram, usam, ou dispõem de produtos, de serviços, de ideias, ou de experiências para satisfazer a necessidades e a desejos.". Ao expressarem suas opiniões acerca de itens lançados no mercado, as blogueiras persuadem uma legião de seguidores; seja positiva ou negativamente.

Neste sentido, propõe-se como objeto de estudo esta nova ferramenta de comunicação e o seu potencial de impacto sobre as diversas esferas da vida humana. Pretendeu-se observar o papel dos chamados blogueiros como grupos de referência, analisando o processo de adoção e difusão da moda através da interatividade proposta pelos blogs.

31 Pessoas famosas no ambiente virtual, seja por número elevado de seguidores, fãs, curtidas, comentários ou outro meio de mensuração da influência digital. 
Os blogs como divulgadores de novos produtos e influenciadores do consumo de moda

Assim, o presente artigo está estruturado em capítulos que abordam aspectos relacionados à problemática em foco. A presente seção, de caráter introdutório, apresenta o tema e sua relevância, além dos objetivos da pesquisa.

O segundo capítulo tem como finalidade fornecer os fundamentos teóricos para a pesquisa de campo, trazendo conceitos como blogs, moda e publicidade online. O terceiro capítulo apresenta a caracterização do trabalho e a metodologia utilizada para a pesquisa de campo.

O quarto capítulo apresenta os dados coletados nessa pesquisa de campo realizada com aplicação de um questionário eletrônico com 508 indivíduos; cujas conclusões e interpretações encontram-se no quinto capítulo. Finaliza-se o artigo, então, com as referências consultadas e citadas no texto.

\section{REVISÃO DA LITERATURA}

Os blogs, também conhecidos por weblogs, são páginas virtuais que oferecem entradas (posts) e comentários. O termo é formado pela palavra web, que se refere à página da internet, e log, ou seja, diário de bordo. 0 primeiro registro do uso da palavra weblog foi em 1997, designando a página pessoal de Jorn Barger, baseada em conexões e comentários, organizada cronologicamente (TERRA, 2012).

Eles podem ser criados a partir de plataformas de publicação gratuitas, como o Blogger, e o Wordpress, ou podem ser hospedados em servidores pagos, que também possuem um formato semelhante aos gratuitos. Os blogs são uma ferramenta de comunicação, à medida que incentivam a troca de mensagens. Conforme Terra (2012, p. 29), “Os blogs, como ferramentas inerentes à internet, apresentam-se como instrumentos de comunicação organizacional que atendem aos padrões de bidirecionalidade, instantaneidade e que dispensam a intermediação.".

Sua grande vantagem é a facilidade no uso, já que não é necessário conhecimentos em programação para acessá-lo: muitas plataformas trazem layouts prontos, permitindo ao usuário que o edite conforme sua preferência. Esse usuário “[...] é o chamado 'blogueiro' (do inglês, blogger) e o universo em que se inserem essas páginas da internet já ganhou também um nome: a 'blogosfera'." (SILVA, 2005 apud TERRA, 2012). Assim, 
Admitindo a "blogosfera" como uma cadeia de blogs interligados em conversações, vemos que, além de ser um canal para a divulgação de informações e um "pontapé inicial” para introduzir sua mensagem, o blog é uma cascata de interações que espalha e divulga mensagens que despertam o interesse da comunidade. (ClPRIANI, 2008, p. 132).

Orduña et al. (2007, p. 143) afirma que, diferentemente dos sites tradicionais, os blogs oferecem múltiplas vantagens que possibilitam uma comunicação mais eficiente, relevante e aberta com um público diversificado. Pelo fato de possuir inúmeras aplicações (espaço pessoal, práticas artísticas, divulgação corporativa, pesquisa, educação, etc.), a blogosfera funciona como uma alternativa à mídia tradicional. Segundo Fernandes e Pimentel (2010, p. 4), "Com esta opção a mais para os receptores, é possível segmentar o assunto do interesse de cada pessoa e poder se aprofundar e participar das mensagens transmitidas através dos blogs."

Um dos diversos assuntos abordados atualmente pelos blogs é a moda: nesta dinâmica, esses dois assuntos apresentam características em comum, como atualização, multiplicidade, efemeridade e individualismo; além de permitir que o usuário crie, publique e divulgue sua própria moda. Os assuntos publicados variam entre desfiles, estilo pessoal, roupas, calçados, maquiagem, acessórios, esmaltes, celebridades, decoração, livros e revistas de moda, entre outros. Estima-se que há mais de 13 milhões de blogs de moda no mundo, com base nas pesquisas específicas do Google. Conforme Rodrigues (2013, p. 130).

Muitos dos blogs de moda e beleza que hoje ganharam fama têm origem em projetos pessoais das respectivas blogueiras, ora como lugar de troca de informação e discussão, ora como interface adicional para colocar em prática e em exposição modos de um consumir próprio do universo feminino.

Os blogs possibilitam que o processo de comunicação seja interativo, pois possuem seus fiéis leitores que leem e comentem as "matérias" postadas; e também linear, pois qualquer indivíduo pode mostrar o que está usando. Normalmente são constituídos de muitas fotos e vídeos, já que a imagem é a linguagem primordial na moda.

Com a velocidade de mudanças no sistema da moda, o blog, entre outras 
Os blogs como divulgadores de novos produtos e influenciadores do consumo de moda

mídias, ganha vantagem pelo seu imediatismo. É possível postar imagens e resenhas das coleções lançadas em tempo real, durante o próprio desfile. Além disso, por oferecerem uma opinião subjetiva e baseada em gostos pessoais, os blogueiros são valorizados e reconhecidos, diferenciando-se das tendências reproduzidas em série por revistas e afins.

Por isso, os blogs e os demais suportes informáticos significaram um avanço na indústria da moda. O uso generalizado da internet, o aparecimento da web 2.0 e a sua ênfase na participação do usuário dentro da engrenagem da comunicação e da publicidade fizeram com que fossem criadas diferentes formas de atrair o consumidor.

Lipovetsky (2009, p. 215) afirma que "no coração da publicidade trabaIham os próprios princípios da moda: a originalidade a qualquer preço, a mudança permanente, o efêmero. Tudo menos dormir no ponto e tornar-se invisível por hábito [...]”.

O velho modelo de publicidade está cada vez mais anacrônico em um mundo de plataformas de mídias personalizadas. A branded content (comunicação por conteúdo) surge como uma nova abordagem e anseia pelo engajamento do consumidor. A comunicação por conteúdo de marca encabeça essas mudanças. O entretenimento de marca será criado com base no que realmente importa aos consumidores; no que de fato cultivará sua atenção, sua razão e sensibilidade (COVALESKI, 2013, p. 40).

É possível perceber essa nova publicidade, com o objetivo de entreter, interagir e compartilhar, como um modelo para as marcas serem percebidas pelos seus consumidores. O Branded Content (conteúdo de marca) que, diferente de uma simples inserção do produto ou serviço num programa, novela ou reality show, propõe-se a gerar conteúdo original para ser absorvido espontaneamente pelo consumidor.

Covaleski (2010, p. 24) explica que "trata-se de uma publicidade mesclada ao conteúdo e transformada em entretenimento; e que também torna-se apta à interatividade e suscetível a ser compartilhada". Filme, show, evento, jogo, dicas de culinária e beleza, roteiros de viagem e gastronomia ou qualquer outro assunto de interesse da audiência pode ser transformado em projeto publicitário, de acordo com esse conceito. O próprio anunciante toma a iniciativa de produzir conteúdo para divertir / entreter e, ao mesmo tempo, criar um vínculo mais afetivo e engajado com o seu target. (SIQUEI- 
RA, 2012).

Assim, fica cada vez mais difícil observarmos uma distinção da atividade publicitária apenas na divulgação objetiva dos produtos, sem quaisquer outros artifícios discursivos e imagéticos que visam o encantamento do consumidor. Isso significa que não há uma coerção concreta exigindo o ato do consumo, mas uma simbólica que requer a participação econômica do indivíduo para que possa ser aceito nos padrões de sociais do comportamento. (BITTENCOURT, 2012).

Essa abordagem é largamente utilizada pelos blogueiros de moda, ao proporem uma identificação com o leitor para a divulgação de produtos. Campbell (2007) acredita que quando alguém procura se relacionar com outro e para isso precisa mostrar sua identidade, acaba se definindo pelos seus gostos e desejos - sendo o consumo a principal atividade para pôr isso em prática. Ao integrar um grupo de referência, os blogueiros permitem que os leitores procurem no consumo a conformidade com a sua imagem.

Dessa maneia, se antes as pessoas visitavam sites oficiais de marcas de seu interesse, hoje elas preferem ler indicações de indivíduos com quem se identificam. As marcas de moda atentaram-se a essas mudanças no comportamento do consumidor e descobriram nos blogs uma oportunidade para entender e envolver seu público-alvo, transformando esse espaço virtual em uma rentável ferramenta publicitária. Tavernari e Murakami (2012) afirmam:

Para o mercado de moda e beleza, os fashion blogs são muito convenientes, pois são uma ferramenta de marketing extremamente barata e de rápido resultado, e a cada dia encontram-se estratégias de uso diferentes para os blogs: anúncios e links na página principal e publieditoriais (anúncios em posts) de todas as formas. Essa última modalidade, aliás, coloca em xeque justamente o caráter de autenticidade discutido anteriormente, uma vez que as empresas apropriam-se do discurso referencial dos posts das blogueiras com finalidade publicitária.

Por ser um setor efêmero e muitas vezes considerado superficial, a moda visa transmitir sua mensagem de maneira leve e divertida, atraindo o cliente de uma forma prazerosa. Como os blogs são acessados em momentos de lazer e descontração, os leitores ficam mais propícios a guardar informações transmitidas pelos autores e até mesmo a efetuarem compras online por eles indicadas; sendo assim uma plataforma muito adequada para esse 
Os blogs como divulgadores de novos produtos e influenciadores do consumo de moda

posicionamento.

\section{MATERIAIS E MÉTODOS}

Tendo em vista que a proposta da presente pesquisa era analisar as influências dos blogs de moda no comportamento de consumo de seus leitores, ela pode ser considerada exploratória e descritiva.

Gil (2009) explica que a pesquisa exploratória tem como finalidade proporcionar maiores informações sobre o assunto que se vai investigar e facilitar a delimitação do tema da pesquisa; já a descritiva envolve o uso de técnicas padronizadas de coleta de dados. Marconi e Lakatos (2010) explicam que os estudos descritivos têm como objetivo conhecer a natureza do fenômeno estudado, a forma como ele se constitui, as características e os processos que dele fazem parte.

Inicialmente, para obter maior compreensão acerca da temática e ampliar o olhar sobre o objeto de pesquisa, foi realizada uma pesquisa bibliográfica a partir de material já elaborado, constituído principalmente de livros e artigos científicos. Após, foi realizada uma pesquisa de campo, cujo instrumento de coleta de dados foi a aplicação de um questionário eletrônico enviado, via internet, aos leitores de blogs de Moda.

Os questionários, como explica Gil (2009), podem ser definidos como a técnica de investigação composta por um conjunto de questões que são submetidas a pessoas com o propósito de obter informações sobre conhecimentos, expectativas, comportamento presente, entre outras. Na maioria das vezes, são propostos por escrito aos respondentes e costumam, nesse caso, ser designados como questionários autoaplicados. Foi desenvolvido um questionário com 11 perguntas - das quais nove eram fechadas (objetivas) e duas abertas (descritivas).

Para garantir o sucesso da aplicação deste, foi primeiramente desenvolvido um questionário piloto, enviado a 20 participantes selecionados aleatoriamente entre o dia 10 de fevereiro e 10 de março de 2014.

Após a aplicação do formulário teste, não houve a necessidade de fazer alterações significativas, pois os conteúdos foram corretamente interpretados por todos os respondentes e as opiniões dos mesmos foram essencialmente favoráveis. Para facilitar o tratamento dos dados, uma das questões descritivas foi transformada em objetiva, resultando num formulário com dez perguntas objetivas e apenas uma descritiva. 
As pesquisas que abrangem um grande universo de elementos impossibilitam a consideração desses em sua totalidade, por essa razão, é muito frequente trabalhar com uma amostra, ou seja, uma pequena parte dos elementos que compõe o universo, selecionando uma parte representativa da população que se pretende estudar. Assim, considera-se que esta é uma pesquisa por amostragem. $O$ universo, ou população da pesquisa são leitores de blogs de moda, sem restrições de idade ou sexo.

A seleção da amostragem para a aplicação do questionário desenvolvido nessa pesquisa é a amostragem por tipicidade. Ela constitui um tipo de amostragem não probabilística e consiste em selecionar um subgrupo da população que, com base nas informações disponíveis, possa ser considerado representativo de toda a população (GIL, 2009).

O questionário final foi aplicado virtualmente para a população brasileira entre os meses de março e julho de 2014, sendo disponibilizado via Google Docs e divulgado por meio das mídias sociais dos pesquisadores. Ele foi respondido por 508 pessoas que acompanham blogs de Moda periodicamente.

O tratamento dos dados levantados foi feito através de um viés qualitativo e quantitativo pois, como sugere Santos Filho e Gamboa (2000, p. 106):

\begin{abstract}
Na pesquisa em ciências sociais, frequentemente são utilizados resultados e dados expressos em números. Porém, se interpretados e contextualizados à luz da dinâmica social mais ampla, a análise torna-se qualitativa. Isto é, na medida em que inserimos os dados na dinâmica da evolução do fenômeno e este dentro de um todo maior compreensivo, é preciso articular as dimensões qualitativas e quantitativas em uma inter-relação dinâmica, como categorias utilizadas pelo sujeito na explicação e compreensão do objeto.
\end{abstract}

Para a análise da pergunta descritiva foi utilizada a técnica Análise de Conteúdo. Para tanto, foi criada a categoria "Postagem Patrocinada", e também criadas Unidades de Contexto (UC) e Unidades de Registro (UR), decorrentes das subunidades de registro identificadas nas respostas. Partindo das UCs e URs encontradas, as respostas foram divididas em afirmativas e negativas, para que fosse possível quantificar a frequência de cada UR, ou seja, o número de vezes em que ela aparecia. 
Os blogs como divulgadores de novos produtos e influenciadores do consumo de moda

A partir da aplicação destes procedimentos metodológicos foi possível cumprir os objetivos propostos nesta pesquisa.

\section{RESULTADOS E DISCUSSÃO}

O questionário desenvolvido foi respondido por 508 pessoas que acompanham blogs de Moda periodicamente, sendo 468 mulheres (92\%) e 40 homens (8\%). A partir das respostas analisadas, constatou-se que o perfil dos leitores de blogs de moda é formado principalmente por mulheres, entre 20 a 35 anos, cursando o ensino superior e que trabalham na área criativa (Moda, Design ou Arquitetura). Com esses dados, é possível perceber que a grande maioria dos leitores pertence à Geração $\mathrm{Y}$, o que corresponde às características de seus integrantes: são curiosos, bem informados e criativos; buscam novas experiências e tecnologias; estão sempre conectados em redes de relacionamento e compartilhamento de conteúdo; e acima de tudo valorizam o consumo, conforme explica Ladeira (2010). A escolaridade e a profissão dos respondentes também estão intimamente ligadas à sua geração, pois se percebe que a maioria encontra-se cursando o Ensino Superior (38\%) e trabalhando em áreas criativas como Moda, Design ou Arquitetura (22\%).

Pelas análises das respostas, percebeu-se que o leitor de blog de moda acompanha, em média, de dois a cinco blogs, os quais acessa uma ou duas vezes por semana. Nesse sentido, observa-se a instantaneidade dessa mídia como uma vantagem em relação aos meios de comunicação tradicionais: enquanto o leitor visita o blog semanalmente, no mínimo; uma revista especializada em moda é distribuída apenas uma vez por mês. Com a velocidade das postagens e frequência de acessos dos usuários, a opinião de blogueiras conquistou o mesmo peso que um crítico de jornal ou revista. Weinberg (2010, p. 28) afirma:

Muitos blogueiros que postam frequentemente estão em um elevado status on-line devido à onipresença da internet: eles se tornaram especialistas no assunto, e são capazes de educar não apenas seus próprios consumidores, mas também companheiros que buscam seu conselho. 
Dentro desse contexto, Hinerasky (2010) também explica que a atração e fidelização dos leitores - ou seja, o motivo pelo qual um mesmo usuário visita um blog uma ou duas vezes por semana - tem relação com a efemeridade da moda, que projeta a necessidade de atualização das páginas. Graças ao sistema dessa mídia, é possível postar imagens e resenhas das coleções lançadas em tempo real e trazer novidades tão logo elas surjam, diferentemente de uma publicação impressa, cuja pauta deve ser montada com dias de antecedência. Por isso, os blogs atraem marcas que desejam uma publicidade atual e imediata, além de leitores fiéis que visitam regularmente as páginas.

Apesar desse comportamento fiel de acompanhamento, a grande maioria dos leitores não costuma fazer comentários nos posts dos blogs visitados. O resultado mostrou que 444 pessoas, ou seja, $87 \%$ dos respondentes não publicam opiniões nos textos das blogueiras. Terra (2012, p. 46) afirma que "O blog permite a construção coletiva de intimidade a partir do momento em que um comentário se interpõe nas páginas e mistura pessoas, pontos de vista, interesses, preferências." Entretanto, percebe-se que a maioria das autoras não costuma responder as interações feitas em sua página, o que pode ser um fator para desestimular o leitor a deixar sua opinião nas publicações.

Quando questionados sobre quais blogs costumam ler, os participantes confirmaram a liderança do blog Garotas Estúpidas no país em termos de audiência. A página tem a melhor colocação entre os blogs brasileiros inseridos no ranking Signature 9 (2014) e mostrou ser acompanhada por $45 \%$ dos respondentes, ou seja, 230 pessoas. Como era permitido assinalar mais de uma resposta, 226 pessoas também costumam ler outros blogs senão os que figuram o ranking, mostrando a importância de outras páginas para o leitor. Algumas páginas tiveram diversas citações, como é o caso do Blog da Thássia (33 menções), Sonhos de Crepom (28 menções), Monalisa de Batom (22 menções) e Lala e Maria Rudge (20 menções). 
Os blogs como divulgadores de novos produtos e influenciadores do consumo de moda

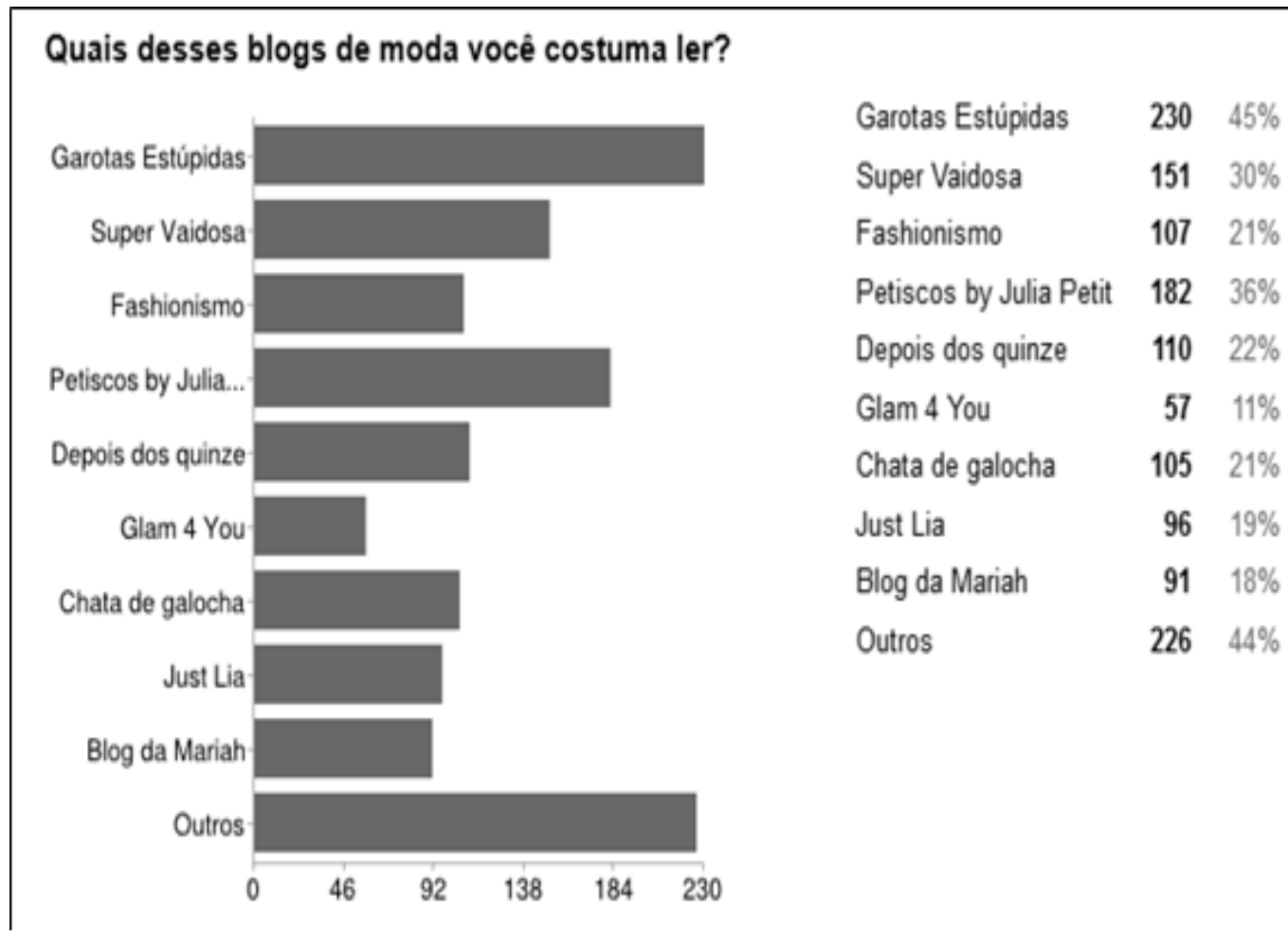

Figura 1 - Blogs preferidos pelos respondentes

Fonte: Dados da pesquisa (2014)

No que se refere à preferência de publicação, observa-se que os leitores de blogs de moda são atraídos por conteúdos essencialmente de moda e beleza, isto é, tendências, look do dia e temas relacionados a cosméticos. Tavernari e Murakami (2012) explicam que esse tipo de publicação constrói uma representação do feminino carregada de veracidade e autenticidade, permitindo às autoras que expressem sua própria identidade.

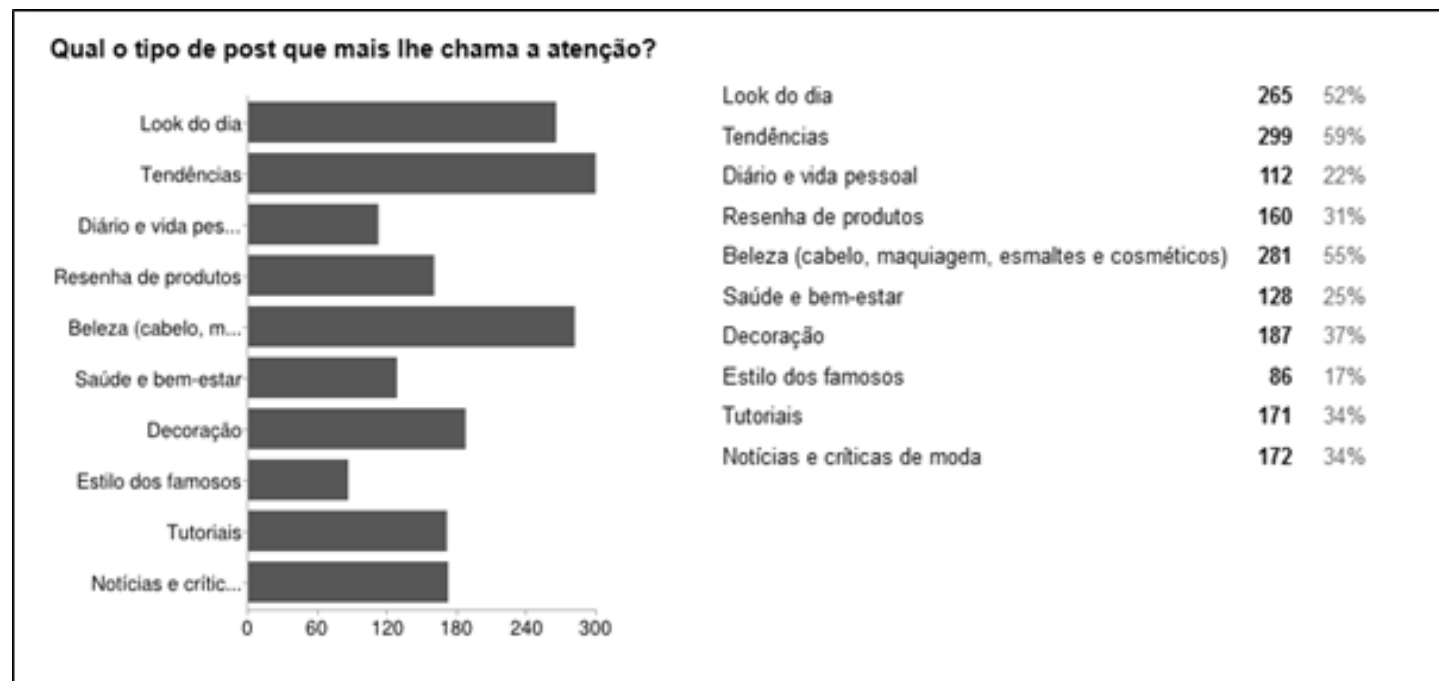

Figura 2 - Publicações preferidas pelos leitores

Fonte: Dados da pesquisa (2014) 
A relação do leitor com a publicidade existente nos blogs de moda foi questionada em três vertentes: através de banners de propaganda, por meio de dicas da blogueira e com base no estilo da autora. Em um primeiro momento, observou-se que a inserção de banners publicitários não atrai muito o leitor. Apesar de praticamente a metade deles (44\%) já terem clicado em uma divulgação desse estilo, apenas $25 \%$ dos respondentes compraram o produto anunciado.

Por outro lado, a inserção de publicidade nos próprios posts influencia diretamente o comportamento de compra do leitor, sendo que $77 \%$ dos participantes já consumiram algum produto por indicação de blogueiras e 69\% inspiraram-se nelas para adquirir algo. Miranda (2008) explica que isso acontece porque o indivíduo possui tendência psicológica à imitação, pois esta proporciona a satisfação de não estar sozinho em suas ações. Ao imitar, não só se transfere a atividade criativa, mas também a responsabilidade sobre a ação dele para o outro. A necessidade de imitação vem da necessidade de similaridade.

Tal processo é conhecido como mimese, ou seja, a construção do eu através da apropriação da aparência e do comportamento do outro. Tenta-se superar os demais membros da própria classe social e tenta-se alcançar o nível da que está acima, imitando-a. A imitação e a diferenciação são processos fundamentais na construção da identidade. A apropriação do outro ocorre com a necessidade de transformar sua personalidade ou aparência para satisfazer necessidades de viver em grupo e emitir mensagens de pertencimento ou status social elevado (SVENDSEN, 2010).

O status social das blogueiras impõe o desejo de transformar-se em personagens idênticos a elas, seja na aparência, na indumentária ou no comportamento, e o principal modo que se pode ter acesso a isso é através da compra. Por isso, as autoras atuam como verdadeiros displays de divulgação, tornando-se referências para consumidores e consolidando um sistema marcado pela efemeridade. Miranda (1998) as conceitua como líderes de opinião, ou seja, seus conselhos são adotados por outros indivíduos graças ao seu conhecimento, discussão e interesse sobre o tema.

As blogueiras são capazes de influenciar atitudes do usuário, o que legitima a importância a elas creditada. Essa credibilidade está ligada ao fato de que os blogs não estão submetidos às mesmas restrições que as mídias tradicionais e possuem a vantagem da pessoalidade. Em outras palavras, os blogs possuem liberdade editorial e rapidez na disseminação da informação, 
Os blogs como divulgadores de novos produtos e influenciadores do consumo de moda

não estando sujeitos a filtros; e são criados por "pessoas comuns". Os participantes da pesquisa comprovaram isso ao afirmar que a publicidade inserida nos blogs tem tanta credibilidade quanto às propagandas publicadas em revistas de moda.

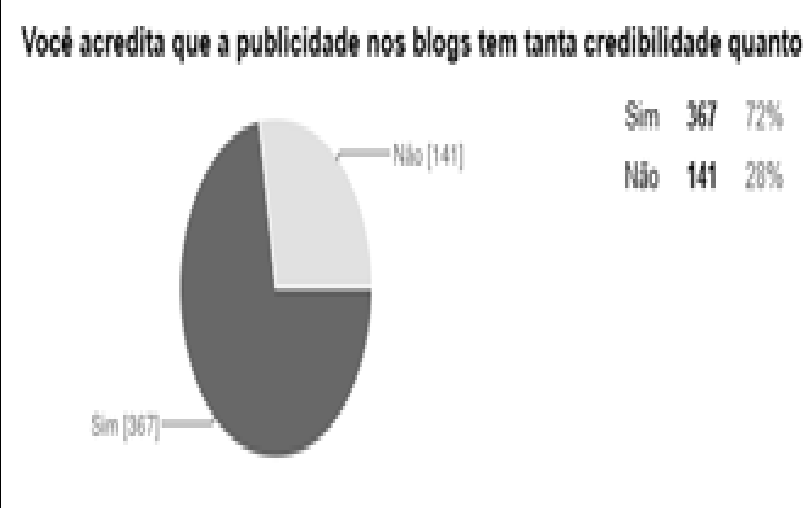

Figura 3 - Atribuição de credibilidade aos blogs de moda Fonte: Dados da pesquisa (2014)

A última questão do formulário foi: "Você acredita que uma postagem patrocinada tenha menos credibilidade do que um post do dia-a-dia real da blogueira?". A mesma permitia a inserção de comentários do participante, por isso seus dados foram tratados através da técnica de Análise de Conteúdo, já mencionada anteriormente. Esta pergunta foi categorizada como "Postagem Patrocinada", auxiliando na análise das Unidades de Contexto (UC) e identificação das Unidades de Registro (UR) criadas. Partindo das UCs e URs encontradas, as respostas foram divididas em afirmativas e negativas, para que fosse possível quantificar a frequência de cada UR, isto é, o número de vezes em que ela aparecia.

Pergunta: Você acredita que uma postagem patrocinada tenha menos credibilidade do que um post do dia-a-dia real da blogueira?

Categoria: Postagem Patrocinada 


\begin{tabular}{|l|l|}
\hline \multicolumn{2}{|l|}{ Respostas afirmativas } \\
\hline \multicolumn{1}{|c|}{ Unidade de Registro (UR) } & \multicolumn{1}{|c|}{ Frequência } \\
\hline Postagem está sendo paga & UR comentada 46 vezes \\
\hline $\begin{array}{l}\text { Blogueira só diz o que a marca quer. } \\
\text { Informação manipulada }\end{array}$ & UR comentada 35 vezes \\
\hline $\begin{array}{l}\text { A blogueira perde credibilidade ao fazer } \\
\text { postagem patrocinada }\end{array}$ & UR comentada 05 vezes \\
\hline
\end{tabular}

Quadro 1 - Exploração do conteúdo das respostas afirmativas Fonte: Dados da pesquisa (2014)

\begin{tabular}{|c|c|}
\hline \multicolumn{2}{|c|}{$\begin{array}{l}\text { Pergunta: Você acredita que uma postagem patrocinada tenha menos credibilidade do } \\
\text { que um post do dia-a-dia real da blogueira? }\end{array}$} \\
\hline \multicolumn{2}{|l|}{ Categoria: Postagem Patrocinada } \\
\hline \multicolumn{2}{|l|}{ Respostas negativas } \\
\hline Unidade de Registro (UR) & Frequência \\
\hline $\begin{array}{l}\text { Se a postagem patrocinada não sair do } \\
\text { foco do blog }\end{array}$ & UR comentada 08 vezes \\
\hline $\begin{array}{l}\text { Se a blogueira sinalizar que a postagem é } \\
\text { patrocinada }\end{array}$ & UR comentada 05 vezes \\
\hline Se o blog já tiver credibilidade (histórico) & UR comentada 20 vezes \\
\hline
\end{tabular}

Quadro 2 - Exploração do conteúdo das respostas negativas Fonte: Dados da pesquisa (2014)

Partindo disso, observou-se que a maioria dos leitores não atribui tanta credibilidade às postagens pagas quanto às postagens autorais das blogueiras de moda. Muitos dos comentários mencionaram a manipulação de opinião, observando que, se a autora estiver sendo paga, ela irá valorizar o produto ao invés de dar seu real parecer sobre ele: "Ao receber para anunciar um produto, a pessoa não irá apontar nenhuma crítica quanto a qualidade 
Os blogs como divulgadores de novos produtos e influenciadores do consumo de moda

do produto, ou seja, passa uma imagem errônea e distorcida da realidade." (DADOS DA PESQUISA, 2014).

Essa situação pode levar à estratégia ilícita de não sinalizar a publicidade, isto é, a blogueira pode omitir o fato de estar sendo patrocinada com o objetivo de influenciar ainda mais os leitores. Apesar de o leitor parece ser extremamente consciente em relação a este tipo de tendencionismo, ele pode tornar-se vulnerável quando não há sinalização - o que pôde ser observado nas respostas com o tema de publicidade, onde muitos afirmaram seguir "dicas" dada pelas blogueiras:

Eu mesma consumo vários produtos indicados no blogs, e sempre vou em busca de resenhas quando quero consumir algo. Eu acredito que o "boca-a-boca" será sempre a melhor propaganda. Mas no caso da publicidade feita através das blogueiras tem uma vantagem: ali você acompanha os resultados e a influência ao consumo tem uma poder muito maior! (DADOS DA PESQUISA, 2014).

Opondo-se a tais resultados, os participantes também observaram que se o blog já possuir um histórico de credibilidade, a postagem paga tem seu valor. Por isso, os usuários apontam que o patrocínio deve ter "[...] coerência com o restante do conteúdo apresentado no blog." (DADOS DA PESQUISA, 2014). Blogs renomados conseguem repercussão mesmo com postagens pagas sinalizadas, pois o sucesso adquidirido faz com que leitores os considerem extremamente confiáveis. Porém, ainda assim devem passar pelo "crivo" dos leitores através da seleção de publicidade, ou seja, o blog deve apresentar patrocinadores que dizem respeito ao estilo da sua página.

[...] depende muito do produto sendo patrocinado e de como a propaganda é feita. Precisa ser no mínimo plausível que a blogueira $\mathrm{x}$ fale bem de tal produto. Precisa existir um histórico de produtos parecidos no blog, pra não denunciar tanto a propaganda, $\mathrm{e}$ assim, perder toda a credibilidade. (DADOS DA PESQUISA, 2014).

Alguns leitores consideram, inclusive, que a publicidade paga traz mais credibilidade aos blogs, pois a empresa vincula seu nome à página:

Acredito ter mais ênfase em um blog patrocinado, pois se não conhecemos a pessoa que posta, não teremos certeza se é confiável. E tendo patrocínio, acaba levando um nível de confiança, uma vez, que alguém deixa o nome de sua "empresa" relacionado com o trabalho/dicas/opiniões de alguém. (DADOS DA PESQUISA, 2014). 
Dessa forma, conclui-se que não é possível falar em uniformidade em relação a este fenômeno, tendo em vista a vasta diversidade da blogosfera. Ainda assim, o efeito da publicidade inserida em blogs de moda tem se mostrado eficiente, pois muitos leitores a tomam como verdade. Fernandes e Pimentel (2010, p. 9) afirmam que "[...] os blogueiros lucram financeiramente e os anunciantes ganham a oportunidade de aumentar as vendas, expandir seus negócios para o Brasil inteiro e aumentam a lembrança da marca perante os consumidores.".

Assim, esse tipo de blog pode ser percebido como uma nova ferramenta midiática e um novo suporte publicitário, criando líderes de opinião que influenciam uma legião de seguidores. Porém, conforme diversos autores pontuam, ainda é necessário buscar um caminho ideal para esse veículo no que diz respeito à publicidade e à forma de relacionamento com o leitor neste tipo de publicação.

\section{CONSIDERAÇÕES FINAIS}

A presente pesquisa apresentou os resultados de um questionário aplicado acerca do comportamento do leitor de blogs de moda, cujos dados foram tratados através de estatística simples, nas perguntas objetivas, e da técnica de Análise de Conteúdo, nas questões descritivas. Foram coletadas 508 respostas, entre homens e mulheres de 13 a 63 anos, que informaram suas preferências em relação às publicações, propagandas e outros aspectos dos blogs de moda.

As respostas obtidas através do questionário mostraram que os leitores de blogs de moda brasileiros são fiéis e visitam as páginas regularmente, porém, a grande maioria não costuma fazer comentários nos posts visitados. A interação comunicacional é, por vezes, defasada, já que as autoras também não costumam responder às publicações. No que diz respeito à publicidade, os leitores mostraram serem mais influenciados por opiniões e pelo estilo da própria blogueira do que por banners e propagandas inseridas na página.

Portanto, quando a publicidade aparece em posts, ela mostrou ser vantajosa, pois $72 \%$ dos respondentes afirmaram que dão tanta credibilidade aos blogs quanto às revistas especializadas em moda. Mas não há uma uniformidade nesse processo, pois muitos dos comentários mencionaram a manipulação de opinião, observando que, se a autora estiver sendo paga, ela irá valorizar o produto ao invés de dar seu real parecer sobre ele. Tais 
Os blogs como divulgadores de novos produtos e influenciadores do consumo de moda

resultados foram importantes para mostrar a necessidade de se encontrar um modelo ideal de inserção de publicidade nos blogs. Por não serem considerados um tipo de mídia tradicional, ainda não há uma regulamentação específica que beneficie tanto leitor quanto autor nessa nova ferramenta.

Dessa forma, a presente pesquisa mostrou que os blogs relacionam-se intimamente com a moda, no que diz respeito à efemeridade, multiplicidade e até mesmo na difusão de tendências. Eles são os atuais ditadores de tendências e formadores de opinião, fazendo com que um único post, dependendo da crítica - se positiva ou negativa - pode tornar um produto um sucesso ou um fracasso de vendas. 


\section{REFERÊNCIAS}

BITTENCOURT, Renato Nunes. Sedução para o consumo. Revista Filosofia - Ciência e Vida, n. 66, 2012. Disponível em: <http://portalcienciaevida.uol.com.br/esfi/Edicoes/66/ artigo244877-1.asp>. Acesso em: 20 jun. 2014.

CAMPBELL, Colin. Eu compro, logo sei que existo: as bases metafísicas do sujeito moderno. In: BARBOSA, Lívia; CAMPBELL, Colin. Cultura, Consumo e Identidade. Rio de Janeiro: FGV, 2007.

CIPRIANI, Fábio. Blog Corporativo: aprenda como melhorar o relacionamento com seus clientes. São Paulo: Novatec, 2008.

COVALESKI, Rogério. Publicidade Híbrida. Curitiba: Maxi Editora, 2010.

COVALESKI, Rogério. Idiossincrasias Publicitárias. Curitiba: Maxi Editora, 2013.

FERNANDES, Lívia Bisatto; PIMENTEL, Franciele Paes. O efeito da publicidade em blogs de moda. Revista Advérbio, Cascavel, v. 5, n. 10, 2010.

GIL, Antônio Carlos. Métodos e técnicas de Pesquisa Social. São Paulo: Atlas, 2009.

HINERASKY, Daniela. Jornalismo de moda no Brasil: da especialização à moda dos blogs. In: $6^{\circ}$ Colóquio de Moda, 2010, São Paulo. Anais... São Paulo: Colóquio de Moda, 2010.

LADEIRA, Wagner Junior. Estilos de Tomadas de Decisão: Uma Investigação em Gerações Diferentes. Revista de Administração da UNIMEP, Piracicaba, v.8, n.3, p. 184-206, 2010.

LIPOVETSKI, Gilles. O império do efêmero: a moda e seu destino nas sociedades modernas. São Paulo: Companhia da Letras, 2009.

MARCONI, Marina de Andrade; LAKATOS, Eva Maria. Metodologia Científica. São Paulo: Atlas, 2010.

MIRANDA, Ana Paula Celso de. Comportamento de Consumo em vestuário de moda feminino: análise exploratória. 1998. 124f. Dissertação (Mestrado em Administração) Universidade Federal do Paraná, Curitiba, 1998.

MIRANDA, Ana Paula. Consumo de Moda: relação pessoa-objeto. São Paulo: Estação das Letras e Cores, 2008.

ORDUÑA, Octavio I. Rojas et al. Blogs: revolucionando os meios de comunicação. São Paulo: Thomson Learning, 2007.

RODRIGUES, Graziela Fernanda. Blogs de moda e beleza: espaço mercadológico de interação sentido e axiologias. 2013. Dissertação (Mestrado em Comunicação e Semiótica) Pontifícia Universidade Católica de São Paulo, São Paulo.

SANTOS FILHO, José de Camilo dos; GAMBOA, Silvio Sánches. (Orgs.). Pesquisa Educacional: quantidade-qualidade. São Paulo: Cortez, 2000. 3. ed.

SIGNATURE 9. The 99 Most Influential Fashion \& Beauty Blogs: Spring 2014. Disponível em: <http://www.signature9.com/style-99>. Acesso em: 14 jun. 2014.

SIQUEIRA, Olga Angélica Santos. Publicidade e Branded Content como geradores de 
Os blogs como divulgadores de novos produtos e influenciadores do consumo de moda

capital emocional: análise do viral Eduardo e Mônica, da Vivo. Trabalho apresentado no XXXV Congresso Brasileiro de Ciências da Comunicação: Fortaleza, 2012.

SVENDSEN, Lars. Moda uma filosofia. Rio de Janeiro: Zahar, 2010.

TAVERNARI, Mariana Della Dea; MURAKAMI, Mariane Harumi. O gênero dos Fashion Blogs: representações e autenticidades da moda e do feminino. Revista Rumores, São Paulo, v. 12, n. 2, p. 85-106, 2012.

TERRA, Carolina Frazon. Blogs corporativos: modismo ou tendências? Rio de Janeiro: SENAC Rio, 2012.

WEINBERG, Tamar. As novas regras da comunidade: marketing na mídia. Rio de Janeiro: Alta Books, 2010. 


\section{Thaissa Schneider}

Mestre em Design pela Universidade do Estado de Santa Catarina (UDESC), especialista em Design de Moda pela Universidade Estadual de Londrina (UEL); graduada em Moda pela Universidade do Estado de Santa Catarina (UDESC); é professora do curso Moda na Católica de Santa Catarina em Jaraguá do Sul, e de Design de Moda na Unifebe, em Brusque. Blumenau, SC, Brasil.

thai@terra.com.br

\section{Laura Pedri Pereira}

Mestranda em Design pela Universidade do Estado de Santa Catarina (UDESC), aluna da especialização em Gestão e Criação de Moda pela Católica de Santa Catarina em Jaraguá do Sul, bacharel em Moda pela Católica de Santa Catarina em Jaraguá do Sul, com extensão em Jornalismo de Moda pela EnModa - Escola de Empreendedores e em Mídias Sociais para Moda pela University of Arts London - London College of Fashion. Jaraguá do Sul, SC, Brasil. laurapereira@unerj.br

RECEBIDO EM: 23/10/2015

APROVADO PARA PUBLICAÇÃO: 28/10/2015 